\title{
Post-Operative Superior Mesenteric Artery Syndrome Following Retroperitoneal Sarcoma Resection
}

\author{
Liam H. Wong ${ }^{1}\left(\right.$, Thomas L. Sutton ${ }^{2}$, Ryan G. Spurrier ${ }^{3,4}$, Andrew F. Zigman ${ }^{3}$ and \\ Skye C. Mayo ${ }^{2,5, *}$ \\ 1 School of Medicine, Oregon Health \& Science University (OHSU), 3181 SW Sam Jackson Park Rd, \\ Portland, OR 97239, USA; wonli@ohsu.edu \\ 2 Division of Surgical Oncology, Oregon Health \& Science University (OHSU), 3181, SW Sam Jackson Park Rd, \\ Portland, OR 97239, USA; suttoth@ohsu.edu \\ 3 Division of Pediatric Surgery, Oregon Health \& Science University (OHSU), 3181 SW Sam Jackson Park Rd, \\ Portland, OR 97239, USA; rspurrier@chla.usc.edu (R.G.S.); andrew.f.zigman@kp.org (A.F.Z.) \\ 4 Division of Pediatric Surgery, Children's Hospital of Los Angeles, 4650 Sunset Blvd, \\ Los Angeles, CA 90027, USA \\ 5 OHSU Knight Cancer Institute, 3181 SW Sam Jackson Park Rd, Portland, OR 97239, USA \\ * Correspondence: mayos@ohsu.edu; Tel.: +1-(503)-494-5501; Fax: +1-(503)-494-1211
}

Received: 4 December 2020; Accepted: 16 December 2020; Published: 24 December 2020

check for updates

\begin{abstract}
Superior mesenteric artery (SMA) syndrome is an uncommon phenomenon caused by the compression of the third portion of the duodenum between the aorta and the SMA. Here, we present a previously healthy 15-year-old male who presented with early satiety and $20 \mathrm{~kg}$ weight loss. Computed tomography (CT) demonstrated a massive retroperitoneal liposarcoma displacing the entire small intestine into the right upper quadrant. Following resection of the large mass, the patient was intolerant of oral intake despite evidence of bowel function. Abdominal CT revealed a narrowing of the duodenum at the location of the SMA. A nasojejunal feeding tube was placed past this area, and enteral nutrition was initiated before slowly resuming oral intake. Post-operative SMA syndrome is an uncommon complication but should be considered in patients intolerant of oral intake following resection of large abdominal tumors associated with extensive retroperitoneal fat loss, even in the absence of concomitant major visceral resection.
\end{abstract}

Keywords: superior mesenteric artery syndrome; SMA syndrome; retroperitoneal sarcoma; duodenal obstruction; gastrointestinal symptom

\section{Case Report}

A previously healthy 15-year-old male was referred to our hospital presenting with early satiety, $20 \mathrm{~kg}$ weight loss (body mass index $=18.1 \mathrm{~kg} / \mathrm{m}^{2}$ ), and abdominal fullness on exam. Abdominal computed tomography (CT) revealed a massive retroperitoneal tumor shifting the entire small bowel into the right upper quadrant, with significant lateral displacement of the superior mesenteric artery (SMA) from its normal anatomic course (Figure 1). The tumor was compressing all intra-abdominal organs, including the stomach, likely causing his symptoms of early satiety. Percutaneous biopsy of the mass demonstrated a well-differentiated liposarcoma. Chest CT did not show any evidence of lung metastases. 


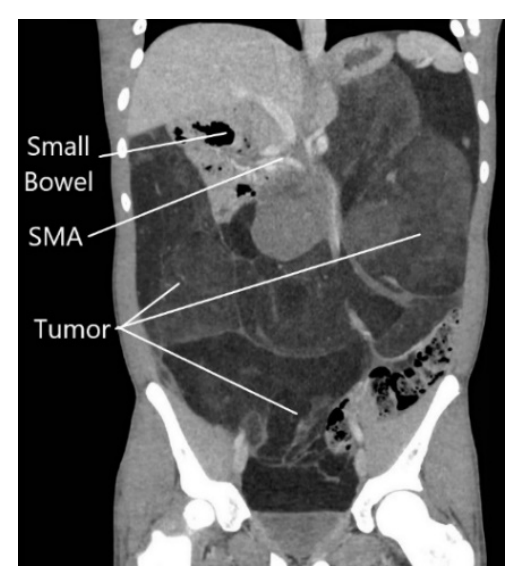

Figure 1. Abdominal computed tomography scan showing massive retroperitoneal liposarcoma, with displacement of the small intestine to the right upper quadrant.

The patient underwent resection of the $11.1 \mathrm{~kg}, 70 \mathrm{~cm}$ mass without en bloc visceral resection; surgical margins were negative with no capsular disruption or intra-operative tumor spillage. It is worth noting that the duodenum was visualized crossing the midline, and the ascending, transverse, and descending colons were in their normal anatomic positions, excluding pre-existing malrotation. At the conclusion of the resection, he was noted to have near-complete absence of lipomatous tissue in his retroperitoneum. Post-operatively, he was persistently intolerant of diet advancement; despite apparently successful attempts at nasogastric decompression with evidence of bowel function, he demonstrated persistent bilious emesis with a benign abdominal exam. An upper gastrointestinal series revealed abrupt cutoff of contrast in the mid-duodenum, with significantly delayed transit of contrast distally (Figure 2). Abdominal CT demonstrated duodenal compression by the SMA with a reduced aortomesenteric distance of $8 \mathrm{~mm}$, diagnostic of SMA syndrome (Figure 3). A nasojejunal feeding tube was placed fluoroscopically; the patient quickly tolerated goal tube feeds and began gaining weight. He remained nil per os for 4 weeks after discharge with continued weight gain, before slowly resuming oral intake. The patient's intolerance to oral intake has resolved; he is now independent of tube feedings and has returned to near the 50th weight percentile for his age and height.

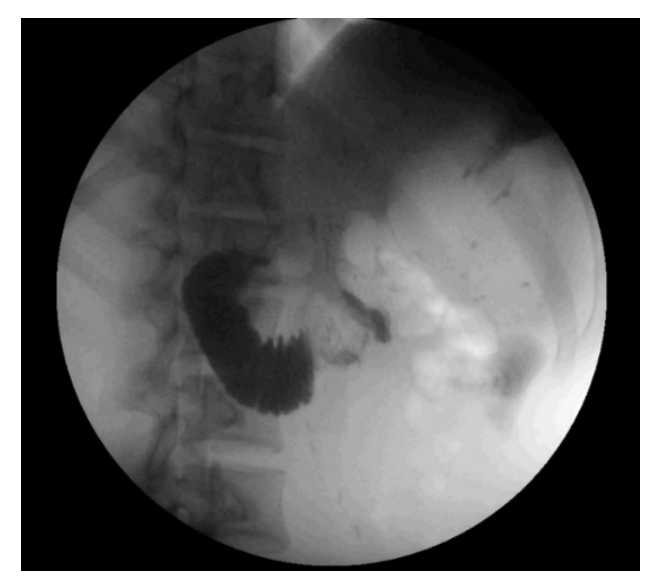

Figure 2. Representative image from upper gastrointestinal series showing abrupt cutoff of oral contrast in the mid-transverse duodenum, suggestive of superior mesenteric artery syndrome. 


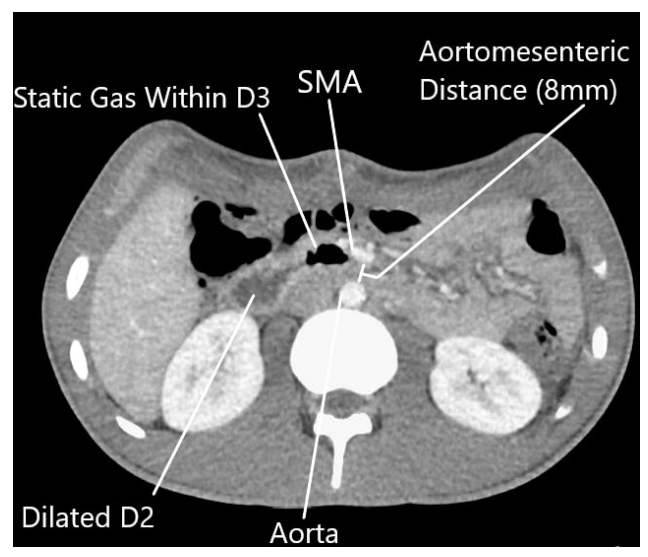

Figure 3. Abdominal computed tomography scan showing post-operative return of superior mesenteric artery to normal anatomic position, with reduced aortomesenteric distance $(8 \mathrm{~mm})$. (SMA-superior mesenteric artery, D2 - second portion of the duodenum, D3 - third portion of the duodenum).

\section{Discussion}

Superior mesenteric artery syndrome is an uncommon phenomenon with an estimated incidence in the general population between $0.013 \%$ and $0.3 \%$ [1-3]. SMA syndrome is defined as the compression of the third portion of the duodenum between the aorta and the SMA, leading to a functional point of obstruction. The SMA arises from the abdominal aorta at the first lumbar vertebral body level, and typically maintains an angle of 38 to 65 degrees relative to the aorta, with an aortomesenteric distance of 10 to $28 \mathrm{~mm}$, between which the duodenum traverses [4]. The root cause of SMA syndrome is narrowing of this distance, causing compression of the duodenum $[2,4]$.

Patients with SMA syndrome predominantly present with a history of chronic abdominal complaints characterized by signs and symptoms of duodenal obstruction but varying due to the degree of duodenum compression [3]. Symptoms can range from postprandial pain and nausea to complete bowel obstruction symptoms [1]. Diagnosis is based on clinical evidence of intolerance of oral intake with diagnostic imaging to show obstruction at the third portion of the duodenum [1]. Upper gastrointestinal series classically show gastric and proximal duodenal dilation, with an abrupt termination of the contrast material column in the third portion of the duodenum [3]. CT and magnetic resonance scans allow visualization of the site of duodenal obstruction relative to the SMA and precise measurement of the aortomesenteric angle and distance [1,3]. CT criteria for the diagnosis of SMA syndrome include an aortomesenteric angle of less than 22 degrees or an aortomesenteric distance of less than 8 to $10 \mathrm{~mm} \mathrm{[5].}$

Epidemiologically, females are more commonly affected, with two-thirds of patients 10 to 40 years of age [1]. Risk factors for developing SMA syndrome fall into three categories: severe rapid weight loss, external and intra-abdominal compression, and mesenteric tension [3]. SMA syndrome is most commonly found in rapid weight loss with wasting of retroperitoneal adipose tissue that bolsters the aortomesenteric distance as seen in our patient. Rapid weight loss and wasting conditions can lead to the loss of this retroperitoneal fat tissue, resulting in the narrowing of the aortomesenteric angle $[2,6]$. This phenomenon has been observed in the setting of AIDS [7], cancer [8,9], eating disorders [4], cerebral palsy [4], substance abuse [10], and other catabolic and malabsorptive states [11]. 
Post-operative SMA syndrome following intra-abdominal procedures is extremely rare, but has previously been reported following proctocolectomy and ileoanal pouch anastomosis [12], Nissen fundoplication [13], and aortic aneurysm repair [14]. Corrective spinal surgery for scoliosis, which requires relative lengthening of the spine and results in the narrowing of the aortomesenteric angle, is the most frequently cited cause of post-operative SMA syndrome with an estimated incidence of $2.5 \%[7,15]$. Previously, only one instance of post-operative SMA syndrome following an intra-abdominal mass resection has been reported, occurring following enucleation of a $7 \mathrm{~cm}$ teratoma at the uncinate process of the pancreas [16]. This may have been due to altered local anatomy given the proximity of the uncinate process to the SMA. To our knowledge, the case we have presented is the first reported incidence of SMA syndrome occurring following resection of a large retroperitoneal tumor without visceral resection.

In the present case, the patient's large intra-abdominal tumor was displacing the entire small bowel to the right upper quadrant, effectively "propping open" the aortomesenteric angle as seen by the perpendicular course of the SMA compared with normal anatomy (Figure 1). The patient's pre-operative weight loss, coupled with a rapid return of the small bowel mesentery to its normal anatomic position, likely resulted in the observed SMA syndrome. Another unique feature distinguishing this case from other reported post-operative SMA syndrome cases is that apart from an appendectomy, no native anatomic structures were resected or artificially rearranged in an effort to obtain negative surgical margins.

Lam et al. assessed the clinical symptoms for SMA syndrome following surgical treatment of scoliosis and presented an algorithm on how to treat SMA syndrome [17]. Initial treatment consists of nasogastric decompression and correction of electrolytes and intravenous hydration, followed by enteral nutrition through nasojejunal tube or parenteral nutrition if necessary $[3,10,17]$. These measures aim to increase body weight to promote the restoration of the retroperitoneal fat tissue, increasing the aortomesenteric angle and reducing obstructive symptoms [17,18]. With these measures and advances in both enteral and parenteral nutrition, the need for operative intervention has decreased from $70 \%$ to $14 \%$ from 1974 to 2006 [13].

Operative management is indicated only when conservative management fails [17]. Operative treatments include gastrojejunostomy, Strong's procedure, and duodenojejunostomy. Gastrojejunostomy provides gastric decompression but fails to completely decompress the duodenum, leading to post-operative complications such as blind loop syndrome and persistence of symptoms [19]. In Strong's procedure, the ligament of Treitz is divided to mobilize and derotate the duodenum [20]. While Strong's procedure is not technically difficult and does not involve bowel anastomosis, it has also been shown to have a relatively high failure rate of up to $25 \%$ [4]. In fact, our patient had the ligament of Treitz divided and the third portion of his duodenum fully dissected as part of his liposarcoma resection. Duodenojejunostomy, which provides gastric and duodenal decompression, is performed most frequently in $69 \%$ of surgical cases, with a reported success rate ranging from $80 \%$ to $90 \%[3,6]$.

\section{Conclusions}

Superior mesenteric artery syndrome is an uncommon phenomenon with post-operative SMA syndrome following intra-abdominal procedures even less prevalent. The unifying theme for most cases of post-operative SMA syndrome is a sudden major rearrangement of intra-abdominal anatomy. We report the first case of post-operative SMA syndrome occurring following resection of a giant retroperitoneal liposarcoma. Post-operative SMA syndrome should be considered in patients intolerant of oral intake following resection of large retroperitoneal tumors, even in the absence of major concomitant visceral resection.

Author Contributions: Data collection and manuscript preparation, L.H.W.; data collection, manuscript preparation, clinical care team, T.L.S.; manuscript preparation, clinical care team, R.G.S.; manuscript preparation, clinical care team, A.F.Z.; manuscript preparation, clinical care team, S.C.M. All authors have read and agreed to the published version of the manuscript. 
Funding: This study was undertaken without external or internal funding of any kind.

Institutional Review Board Statement: Ethical review and approval were waived for this study, due to the nature of a case report describing the treatment of a single patient does not meet the federal definition of a human subjects research on the basis that the information in the case report is not generalizable knowledge.

Informed Consent Statement: Informed consent was obtained from all subjects involved in the study.

Data Availability Statement: No new data were created or analyzed in this study. Data sharing is not applicable to this article.

Conflicts of Interest: The authors have no conflicts of interest to disclose.

\section{References}

1. Zaraket, V.; Deeb, L. Wilkie's Syndrome or Superior Mesenteric Artery Syndrome: Fact or Fantasy? Case Rep. Gastroenterol. 2015, 9, 194-199. [CrossRef] [PubMed]

2. Sahni, S.; Shiralkar, M.; Mohamed, S.; Carroll, R.; Jung, B.; Gaba, R.; Yazici, C. Superior Mesenteric Artery Syndrome: The Dark Side of Weight Loss. Cureus 2017, 9, e1859. [CrossRef]

3. Welsch, T.; Büchler, M.W.; Kienle, P. Recalling Superior Mesenteric Artery Syndrome. Dig. Surg. 2007, 24, 149-156. [CrossRef]

4. Merrett, N.; Wilson, R.B.; Cosman, P.; Biankin, A.V. Superior Mesenteric Artery Syndrome: Diagnosis and Treatment Strategies. J. Gastrointest. Surg. 2008, 13, 287-292. [CrossRef]

5. Rabie, M.E.; Ogunbiyi, O.; Al Qahtani, A.S.; Taha, S.B.M.; El Hadad, A.; El Hakeem, I. Superior Mesenteric Artery Syndrome: Clinical and Radiological Considerations. Surg. Res. Pract. 2015, 2015, 628705. [CrossRef]

6. Chrysikos, D.; Troupis, T.; Tsiaoussis, J.; Sgantzos, M.; Bonatsos, V.; Karampelias, V.; Piperos, T.; Kalles, V.; Theodoropoulos, P.; Kakaviatos, D.; et al. Superior mesenteric artery syndrome: A rare case of upper gastrointestinal obstruction. J. Surg. Case Rep. 2019, 2019. [CrossRef] [PubMed]

7. Zhu, Z.Z.; Qiu, Y. Superior mesenteric artery syndrome following scoliosis surgery: Its risk indicators and treatment strategy. World J. Gastroenterol. 2005, 11, 3307-3310. [CrossRef]

8. Lippl, F.; Hannig, C.; Weiss, W.; Allescher, H.-D.; Classen, M.; Kurjak, M. Superior mesenteric artery syndrome: Diagnosis and treatment from the gastroenterologist's view. J. Gastroenterol. 2002, 37, 640-643. [CrossRef]

9. Hines, J.R.; Gore, R.M.; Ballantyne, G.H. Superior mesenteric artery syndrome. Diagnostic criteria and therapeutic approaches. Am. J. Surg. 1984, 148, 630-632. [CrossRef]

10. Barnes, J.B.; Lee, M. Superior mesenteric artery syndrome in an intravenous drug abuser after rapid weight loss. South Med J. 1996, 89, 331-334. [CrossRef] [PubMed]

11. Reckler, J.M.; Bruck, H.M.; Munster, A.M.; Curreri, P.W.; Pruitt, B.A. Colonel Superior Mesenteric Artery Syndrome as A Consequence of Burn Injury. J. Trauma 1972, 12, 979-985. [CrossRef] [PubMed]

12. Goes, R.N.; Coy, C.S.; Amaral, C.A.; Fagundes, J.J.; Medeiros, R.R. Superior mesenteric artery syndrome as a complication of ileal pouch-anal anastomosis. Dis. Colon Rectum 1995, 38, 543-544. [CrossRef] [PubMed]

13. Biank, V.; Werlin, S. Superior mesenteric artery syndrome in children: A 20-year experience. J. Pediatr. Gastroenterol. Nutr. 2006, 42, 522-525. [CrossRef] [PubMed]

14. Luccas, G.C.; Lobato, A.C.; Menezes, F.H. Superior Mesenteric Artery Syndrome: An Uncommon Complication of Abdominal Aortic Aneurysm Repair. Ann. Vasc. Surg. 2004, 18, 250-253. [CrossRef] [PubMed]

15. Kim, J.Y.; Kim, H.S.; Moon, E.S.; Park, J.O.; Shin, D.E.; Lee, G.K.; Ha, J.W.; Jung, Y.S. Incidence and Risk Factors Associated with Superior Mesenteric Artery Syndrome following Surgical Correction of Scoliosis. Asian Spine J. 2008, 2, 27-33. [CrossRef] [PubMed]

16. Sasaki, T.; Saka, R.; Tanaka, N.; Zenitani, M.; Oue, T. A case of superior mesenteric artery syndrome developed after pancreatic teratoma resection. J. Pediatr. Surg. Case Rep. 2017, 17, 37-41. [CrossRef]

17. Lam, D.J.L.; Lee, J.Z.J.; Chua, J.H.Y.; Lee, Y.T.; Lin, K.B.L. Superior mesenteric artery syndrome following surgery for adolescent idiopathic scoliosis: A case series, review of the literature, and an algorithm for management. J. Pediatr. Orthop. B. 2014, 23, 312-318. [CrossRef]

18. Barkhatov, L.; Tyukina, N.; Fretland, Å.A.; Røsok, B.I.; Kazaryan, A.M.; Riis, R.; Edwin, B. Superior mesenteric artery syndrome: Quality of life after laparoscopic duodenojejunostomy. Clin. Case Rep. 2018, 6, 323-329. [CrossRef] [PubMed] 
19. Lee, C.S.; Mangla, J.C. Superior mesenteric artery compression syndrome. Am. J. Gastroenterol. 1978, 70, 141-150. [PubMed]

20. Strong, E.K. Mechanics of arteriomesentric duodenal obstruction and direct surgical attack upon etiology. Ann. Surg. 1958, 148, 725-730. [CrossRef] [PubMed]

Publisher's Note: MDPI stays neutral with regard to jurisdictional claims in published maps and institutional affiliations.

(C) 2020 by the authors. Licensee MDPI, Basel, Switzerland. This article is an open access article distributed under the terms and conditions of the Creative Commons Attribution (CC BY) license (http://creativecommons.org/licenses/by/4.0/). 